\title{
Delayed onset of the South American Summer Monsoon during the Last Glacial Maximum
}

\author{
KeRRY H. COOK AND Ed K. VizY
}

Department of Earth and Atmospheric Sciences, Cornell University, Ithaca, USA; khc6@cornell.edu

\section{Introduction}

Climate conditions in the Amazon basin during the last glacial maximum (LGM, about 21,000 years ago) are actively discussed in the literature. Faunal evidence, noble gas analyses, lake status reconstructions, pollen counts, atmospheric dust, and charcoal records have all been interpreted to provide information about LGM surface moisture and temperature. Much of the evidence suggests that large-scale climate conditions were drier and cooler in the Amazon basin but there is great uncertainty and little quantitative guidance. Proxy data from the high Andes and the Nordeste region of Brazil, e.g., indicate that some regions may have been wetter during the LGM.

Differences in Amazon climate during the LGM are of great interest in the light of current pressing climate change issues. Fundamental questions remain about the stability of tropical climate, and the influence of climate and deforestation on the diversity of tropical vegetation.

\section{Methodology}

There are two ways of learning about past climates, namely, inference based on physical evidence, and computer simulation. Each method has its own strengths and weaknesses. Physical evidence is undeniably real but there may be uncertainties associated with interpretation and dating. Climate modeling provides complete information about the climate state but there are always concerns about accuracy. Both approaches to studying paleoclimate are needed and the most powerful way of reconstructing past climate is to use the two methods in a complementary way, so that they test, challenge and correct each other. The most effective way of doing this is to use a regional climate model (RCM), which is capable of finer resolution than a global model, to bring the paleoclimate simulation closer to the spatial scales of the geological

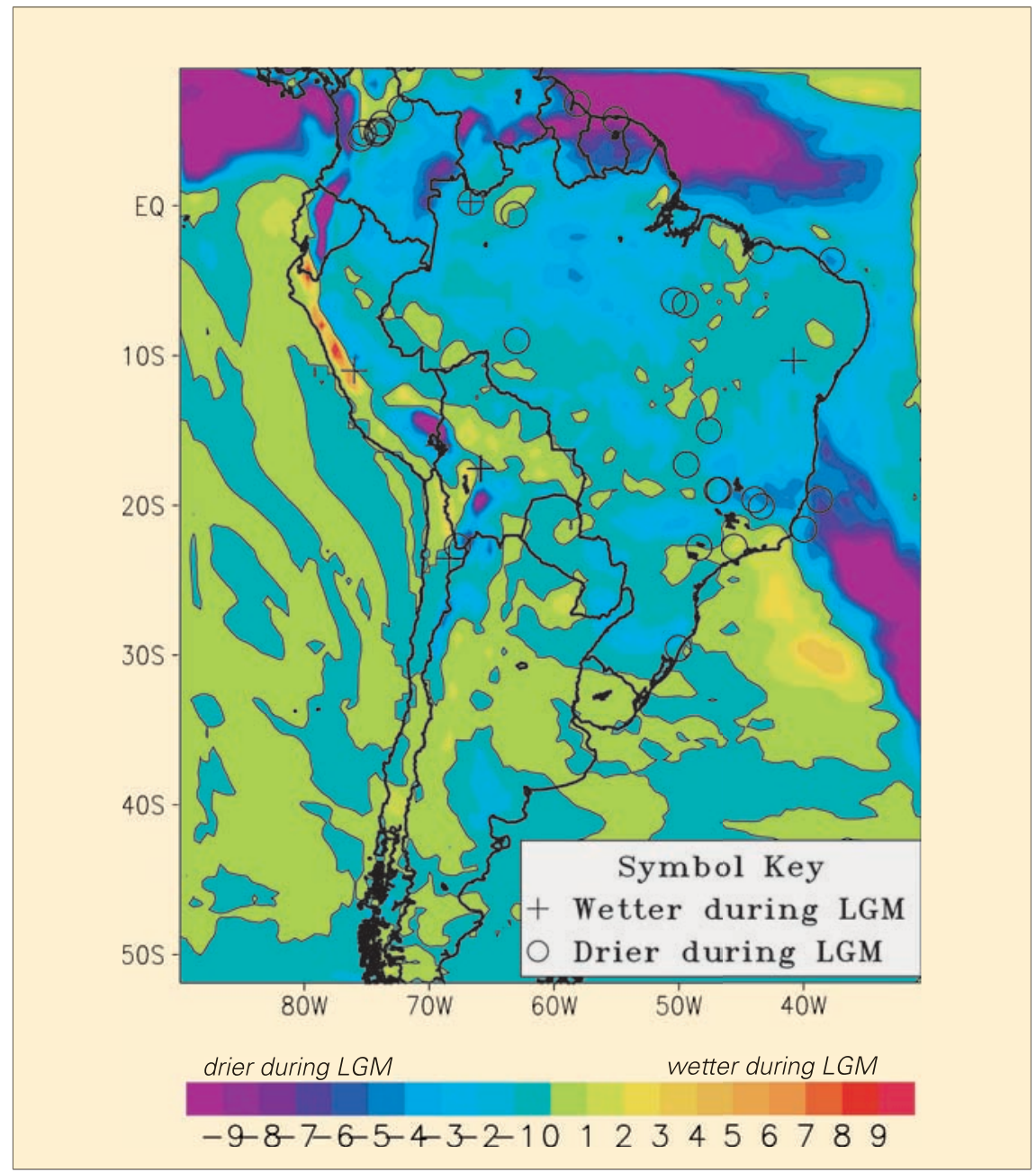

Figure 1: Model domain and total annual precipitation difference between the present day and the LGM simulations. Shading interval is $1 \mathrm{~mm}^{\text {day }}{ }^{-1}$, and the 0 line is contoured. Marks denote LGM precipitation differences from present day interpreted from various proxy reconstruction sites

evidence for a more direct comparison.

Here we use an RCM with $60 \mathrm{~km}$ horizontal resolution and 24 vertical levels, coupled with a potential vegetation model (PVM; Oyama and Nobre, 2004). The model domain, which is unusually large, is shown in Figure 1. A realization of the present day annual climatology was produced by initializing with the observed climatology for $00 Z 15$ October and running through 382 days, with a 1-minute time step and vegetation types held fixed at today's values. A second year was run to verify that the climatology is stable. The regional model replicates the observed climate of South America well, providing a definite improvement over global model simulations, which typically have $200 \mathrm{~km}$ resolution and difficulties resolving the steep Andean topography (Vizy and Cook, 2005).

Paleoclimate application of regional models is complicated by the need to specify lateral boundary conditions for wind velocity, temperature and moisture throughout the depth of the troposphere; such conditions are not available from the geological record. Here, present day lateral boundary conditions based on modern observations are used for both the present day and LGM simulations. This is justified by extensive testing of the sensitivity of 
the simulation to the lateral boundary conditions (Vizy and Cook, 2005), and is likely successful because of the large domain and the tropical location. But remote influences on climate, e.g., in association with the North American ice sheets or sea ice in the North Atlantic, are not included. Such influences can be represented by imposing lateral boundary conditions from global model simulations but we find that our present day simulation is seriously degraded by this lateral boundary forcing, since an accurate simulation of this region's climate is a particular challenge for the lower-resolution global models. In any case, remote forcing may be somewhat influential and warrant future consideration but it is not a primary determinant of South American climate (Lenters and Cook, 1995).

The LGM climate is simulated by making minor changes in the Earth's orbital parameters, reducing the atmospheric $\mathrm{CO}_{2}$ concentration from 330 to 200 ppmv, and by specifying LGM sea surface temperatures following Paul and Schäfer-Neth (2003). Use of the PVM provides independence from having to specify LGM vegetation from geological reconstruction. The output of the coupled RCM/PVM integration consists of a mutually-adjusted solution for both the LGM climate and the LGM vegetation.

\section{Results}

Figure 1 shows simulated differences in annual precipitation for the "LGM" minus "present day" simulations. In most parts of the Amazon basin, total annual rainfall in the LGM simulation is $25-35 \%$ lower than in the present-day simulation, but there are some regions with precipitation increases. A delayed onset of the South American monsoon by 2-3 months is primarily responsible for the simulated LGM aridity (Cook and Vizy, 2006). The annual mean surface temperature over subtropical South America is only slightly cooler than in the present day simulation. The land surface is $1-2 \mathrm{~K}$ cooler for most of the year but warms significantly during the spring, since the delay in the mon-

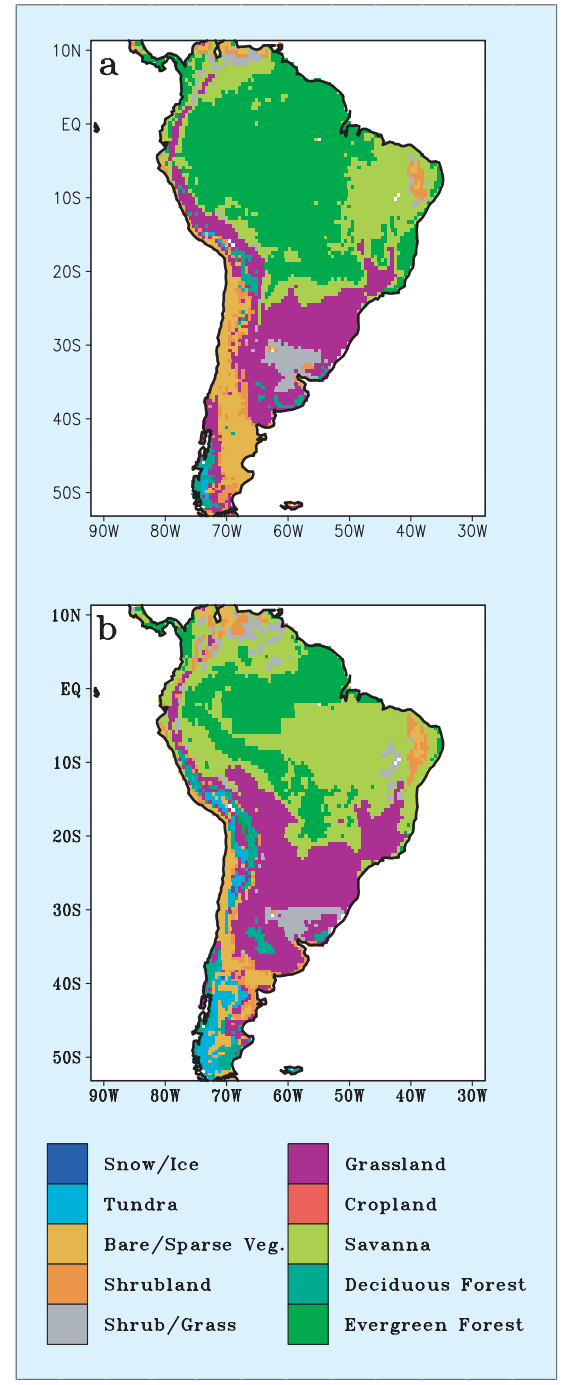

Figure 2: Potential vegetation model vegetation distributions from $(\boldsymbol{A})$ present day and (B) LGM simulations.

soon onset dries the surface and decreases evaporation.

The monsoon onset delay is primarily associated with cool conditions in the tropical Atlantic Ocean. Springtime inflow from the tropical Atlantic into the Amazon basin is much drier in the LGM simulation because of reduced evaporation from the cooler surface waters, so the latent heat content and, therefore, the moist static energy of the low-level air, is lower than in the present day in August, September, and October. In addition, moist static energy levels during the winter months of the LGM are lower than in the present day because land surface temperatures are colder. The result is a delay in the build-up of the low-level moist static energy in the spring, keeping the vertical column stable and inhibiting convection. When the monsoon finally begins in the LGM simulation, rainfall rates are similar to those of the present-day climate.

Figures $2 a$ and $b$ show the vegetation distributions from the present-day and LGM simulations. The good agreement between the modeled and observed vegetation (Fig. $2 a$ ) is a powerful validation of the RCM's ability to capture the present-day climate accurately. In the LGM simulation (Fig. 2b), rainforest vegetation in the central and western Amazon is maintained despite the shorter rainy season and longer dry season. Rainforest in the eastern Amazon, however, cannot be maintained under LGM conditions, and the overall extent of the rainforest is smaller than in the present day.

\section{Conclusions}

Simulations of South America during the LGM with a regional climate model coupled with a potential vegetation model produce a quantitative picture of LGM climate and vegetation distributions that is consistent with the geological proxy data. The model results associate drier conditions in LGM South America with a 2-3 month delay in the onset of the monsoon. Such a shorter, but equally intense, South American monsoon maintains a smaller Amazon rainforest through the glacial period, perhaps with modified species populations. At the same time, this scenario is consistent with evidence of higher charcoal amounts (i.e., increased fires) and atmospheric dust loading due to an extended dry season.

\section{REFERENCES}

Cook, K. H., and Vizy E.K., 2006: South American climate during the Last Glacial Maximum: Delayed onset of the South American monsoon, J. Geophys. Res., 111: D02110, doi:10.1029/ 2005JD005980.

Lenters, J. D., and Cook, K.H., 1995: Simulation and diagnosis of the regional South American precipitation climatology, J. Climate, 8: 2988-3005.

Oyama, M. D., and Nobre, C.A., 2004: A simple potential vegetation model for coupling with the simple biosphere model (SiB). Revista Brasileira de Meteorologia, 19: 203-216.

Paul, A. and Schäfer-Neth, C., 2003: Modeling the water masses of the Atlantic Ocean at the Last Glacial Maximum, Paleoceanography, 18(3), 1058 doi: 10.1029/2002PA000783

Vizy, E.K., and Cook, K.H., 2005: Evaluation of LGM SST reconstructions through their influence on South American climate. J. Geophys. Res., 110: D11105, doi:10.1029/2004JD005415. 